\title{
Association of IL-23R gene rs7517847 T $>$ G SNP and susceptibility to systemic lupus erythematosus: A systematic review and meta-analysis
}

\author{
Danyal Imani ${ }^{1}$, Ramazan Rezaei ${ }^{1}$, Arash Poorsheikhani ${ }^{2}$, Shahab Alizadeh $^{3}$, Mahdi Mahmoudi $^{4^{*}}$ \\ ${ }^{1}$ Department of Immunology, School of Medicine, Tehran University of Medical Sciences, Tehran, Iran \\ ${ }^{2}$ Department of Medical Genetics, School of Medicine, Tehran University of Medical Sciences, Tehran, Iran \\ ${ }^{3}$ Department of Cellular and Molecular Nutrition, School of Nutritional Sciences and Dietetics, Tehran University of Medical \\ Sciences, Tehran, Iran \\ ${ }^{4}$ Rheumatology Research Center, Tehran University of Medical Sciences, Tehran, Iran
}

\begin{abstract}
Previous articles have evaluated the association between IL-23R gene rs7517847 T>G SNP and systemic lupus erythematosus (SLE). Nevertheless, the results of these studies have been inconclusive. The current study is a meta-analysis that assesses the association between IL-23R gene rs7517847 T>G SNP and SLE susceptibility. Literature searches of Medline, Web of Science, and EMBASE databases were performed to recognize all eligible studies published before August, 2016, and the search was updated in July, 2017. The identified studies were independently reviewed by two authors for eligibility based on inclusion criteria. Odds ratios (ORs) and 95\% confidence intervals (CIs) were applied to assess the strength of association in the allelic model, dominant model, recessive model, heterozygotes contrast, and homozygotes contrast. Because evidence of heterogeneity was detected across the studies, the data was pooled using a random-effects model. A sum of four case-control studies with 1348 SLE patients and 1754 healthy subjects were considered in this study. In the combined analysis, no significant association between the IL-23R gene rs7517847 T>G SNP and SLE disease risk was found in any of the genetic models (dominant model: $\mathrm{OR}=0.95,95 \% \mathrm{CI}=0.72-1.18$; allelic model: $\mathrm{OR}=1.08,95 \% \mathrm{CI}=0.95-1.21$; recessive model: $\mathrm{OR}=1.13,95 \% \mathrm{CI}=0.80-1.46$; TG vs. TT: $\mathrm{OR}=0.86,95 \% \mathrm{CI}=0.63-1.08$; and GG vs. TT: $\mathrm{OR}=1.20,95 \% \mathrm{CI}=0.81-$ 1.60). Moreover, no publication bias was observed in any genetic models $(p>0.05)$. First, this study was based on unadjusted ORs. Second, the number of included case-control articles was small. Third, only published English language studies were imported to this meta-analysis. The current meta-analysis suggests that the IL-23R gene rs7517847 T>G SNP might not be related with risk of SLE. More studies are essential to confirm these results. No association was found between the IL-23R gene rs7517847 T>G SNP and SLE risk.
\end{abstract}

Keywords: interleukin-23R, polymorphism, SLE, meta-analysis.

\section{Introduction}

Systematic lupus erythematosus (SLE) is an inflammatory disorder which involves multiple organs such as the skin, kidneys, and the nervous system [1]. It is characterized by chronic inflammation in tissues, autoantibody secretion, and severe organ damage [2]. While there are no exact figures for SLE prevalence in different parts of the world, it is estimated that approximately $12-64$ in 100,000 people suffer from SLE, and SLE is 10 times more prevalent in females than males [3]. SLE has heterogeneous clinical manifestations and complicated genetic features [4]. Although the exact pathogenesis of SLE remains unclear, recent evidence has described a significant familial trend of SLE in monozygotic twins in comparison to healthy subjects [5]. Furthermore, the familial occurrence of SLE has revealed evidence of genetics in the pathogenesis of the disease [6].

Accumulating data has indicated that cytokines and their receptors play crucial roles in the progression of inflammatory disorders such as SLE [7-9]. IL-23 and its receptor (IL-23R) are involved in the pathogenesis of autoimmune disease [10]. The p19 and p40 subunits of IL-23 are expressed mainly by activating phagocytes and dendritic cells [11]. It has been shown that IL-23 plays an essential role in the development and maintenance of IL-17 producing cells [12]. IL-17 induces the synthesis of proinflammatory cytokines including IL-6, TNF- $\alpha$ (Tumor Necrosis Factor), various chemokines, matrix metalloproteinase, and the recruitment of neutrophils from tissue which ultimately leads to chronic inflammation and the destruction of joints and organs [13].

IL-23 exerts its effects through high-affinity

* Corresponding Author: Mahdi Mahmoudi, Email: mahmoudim@tums.ac.ir, Tele-fax: +98-218-822-0067

Received: 04 July 2017; Accepted: 26 August 2017 
binding to the IL-23 receptor (IL-23R) complex [14]. IL-23R includes a common IL-23 receptor and an IL12 receptor $\beta 1$ subunit which are mostly expressed on activated and memory T cells [15]. The IL-23R gene is located on the short arm of chromosome 1, at region 31.3. This gene spans $2.8 \mathrm{~kb}$ and contains 11 exons and 10 introns. The promoter region of the human IL-23R gene are distributed with many single nucleotide polymorphisms [16]. Many studies have demonstrated a strong association between IL-23R polymorphisms and the progression and outcome of several autoimmune disorders, such as ankylosing spondylitis [17], ophthalmopathy [18], Crohn's disease [19], and rheumatoid arthritis [20].

A relatively large number of case-control studies have investigated the association between the IL-23R gene rs7517847 $\mathrm{T}>\mathrm{G}$ SNP and SLE risk. However, inconsistent and inconclusive results have been reported, probably due to the different ethnicity of populations and limited sample sizes. Although some studies have reported a significant association between the IL-23R gene rs7517847 T>G SNP and SLE risk, others have failed to find this association. The current meta-analysis was conducted to obtain an exact estimation of the effect of the IL-23R gene rs7517847 $\mathrm{T}>\mathrm{G}$ SNP and SLE susceptibility.

\section{Evidence Acquisition/ Methods}

This study was performed in accordance with MOOSE (Meta-analysis of observational studies in epidemiology) guidelines [21].

\section{Searches and Data sources}

For this study, a systematic literature search was done on the electronic databases Medline, EMBASE, and Web of Science prior to August, 2016 for all observational studies that had examined the associations between the IL-23R gene rs7517847 T>G SNP and SLE susceptibility; the search was updated in July, 2017. The following syntaxes were used: (interleukin 23 receptor) OR IL-23R) AND (Systemic Lupus Erythematosus OR SLE) AND (polymorphism OR polymorphisms OR SNP OR variation OR mutation). The search strategy was restricted to articles written in the English language and studies involving human populations.

\section{Inclusion criteria}

The articles used in this study were included using the following criteria:

1. Case-control studies that assessed the association of the IL-23R gene rs7517847 T>G SNP with SLE susceptibility;

2. Risk estimates with $95 \%$ confidence intervals that could be extracted or calculated; and

3. Genotype or allele frequency of case and control groups provided by the studies.

The exclusion criteria were as follow:

1. Studies with insufficient information regarding genotype or allele frequency;

2. Abstracts, reviews, comments, and letters; and

3. Republished studies and studies with overlapping subjects.

The identified studies were independently reviewed by two authors for eligibility based on inclusion criteria, and discrepancies were resolved through consensus. The Kappa coefficient as the agreement coefficient between the two investigators was equal to 0.72 , showing an overall good agreement between reviewers.

\section{Extraction of data and quality assessment}

For this meta-analysis, the following information was extracted with the use of a standardized data extraction form: the author's first name, journal and date of publication, ethnicity, country, average age, gender, number of case and control subjects, genotyping method, and the genotype or allele frequency. The Newcastle-Ottawa Scale (NOS) method was employed to evaluate the methodological quality [22]. This quality assessment tool judges studies on the basis of a star system; for this analysis, studies awarded 0-3, 4-6, or 7-9 stars were considered to be low, moderate, or high-quality studies, respectively. The quality assessment and data extraction were performed independently by two investigators.

\section{Statistical analysis}

Adherence to the Hardy-Weinberg equilibrium (HWE) constant was confirmed using the chi-square test [23]. ORs and their 95\% CI were applied to assess the strength of the association between the IL-23R gene rs7517847 T>G SNP and the risk of lupus erythematosus in the following five genetic models: dominant (GG+ TG vs. TT), homozygote comparison (GG vs. TT), recessive (GG vs. $\mathrm{TG}+\mathrm{TT}$ ), heterozygote comparison (TG vs. TT), and allelic (G vs. T) models among groups. In the current metaanalysis, the heterogeneity among studies was assessed using the $\mathrm{X}^{2}$-based $\mathrm{Q}$ test and $\mathrm{I}^{2}$ statistics. Significance level for heterogeneity was set at $p<0.1$ [24]. Because of the remarkable heterogeneity among included studies, a random-effects model was applied. Visual 
inspection of asymmetry in funnel plots, Begg's, and Egger's tests were done to evaluate publication bias ( $p$ $<0.05$ was considered statistically significant) [25]. All statistical analyses were performed with the use of STATA (Version 13.0; Stata Corporation, College Station, TX).

\section{Results}

\section{Characteristics of eligible studies}

The procedures for including/ excluding potential studies are presented in Figure 1. The initial search yielded 463 potentially relevant articles. According to the inclusion criteria, a total of four case-control studies with 1348 SLE cases and 1754 healthy subjects were included in this meta-analysis [26-29]. The studies were done in different regions: one in China [26], one in Hungary [27], one in Spain [28], and one in South Korea [29]. Study publication years ranged from 2007 to 2010. Study characteristics and the genotype and allele frequency of the selected articles are represented in Tables 1 and 2. The genotype frequency of rs7517847 T>G SNP among SLE patients was $32 \%$ in the "TT" genotype, $46 \%$ in the "TG" genotype, and $22 \%$ in the "GG" genotype, while the frequency of the " $\mathrm{T}$ " allele between SLE patients was $55 \%$ and that of the " $G$ " allele was $45 \%$.

\section{Quantitative synthesis \\ Heterogeneity and publication bias}

Based on the inclusion criteria, four studies with 1348 cases and 1754 healthy subjects were analyzed. The summarized results and heterogeneity tests for association between the IL-23R gene rs7517847 $\mathrm{T}>\mathrm{G}$ SNP and the risk of SLE in different genetic models are shown in Table 3. Virtual inspection of funnel plots revealed no evidence of publication bias (Fig. 2).

\section{Meta-analysis for $\quad I L-23 R \quad$ (rs7517847) polymorphism and SLE}

The results of analysis revealed that there was no association between the IL-23R gene rs7517847 $\mathrm{T}>\mathrm{G}$ SNP and the risk of SLE disease in all of the genetic models tested (dominant model (GG+ TG vs. TT): OR= $0.95,95 \% \mathrm{CI}=0.72-1.18$; allelic model $(\mathrm{G}$ vs. $\mathrm{T})$ : $\mathrm{OR}=$ $1.08,95 \% \mathrm{CI}=0.95-1.21$; recessive model (GG vs. TG + TT): $\mathrm{OR}=1.13,95 \% \mathrm{CI}=0.80-1.46$; heterozygote comparison (TG vs. TT): $\mathrm{OR}=0.86,95 \% \mathrm{CI}=0.63-$ 1.08; and homozygote comparison (GG vs. TT): $\mathrm{OR}=$ 1.20, 95\% CI= 0.81-1.60.) (Table 3 and Fig. 3).

\section{Discussion}

The pathogenesis of SLE is a complex process in which both genetic and environmental elements play important roles in its onset and progression [30]. The inflammatory reactions mediated through Th17 lymphocytes are also related to SLE development [31]. IL-23 is one of the important proinflammatory cytokines that is associated with multiple autoimmune diseases, including SLE [32]. Recently several studies have evaluated the association between the IL-23R gene rs7517847 T>G SNP and SLE susceptibility [2629]. Because of inconsistencies in the results, a metaanalysis was needed. Meta-analysis is a strong statistical methodology that combines the findings of independent eligible studies to assess the effects of certain genetic variations on the risk of a disease. The current study is a meta-analysis of published articles which was conducted to evaluated the association between the IL-23R gene rs7517847 T>G SNP and the risk of SLE.

To the best of the authors' knowledge, this was the first meta-analysis study to evaluate the association between the IL-23R gene rs7517847 T>G SNP and SLE risk. Following the literature search, 4 casecontrol articles were involved in this study, including a total of 1348 SLE patients and 1754 healthy subjects. The results of the current study revealed no significant association between the IL-23R gene rs7517847 T>G SNP and SLE susceptibility in any genetic model in the overall samples.

The role of IL-23R in the onset and progression of many autoimmune and inflammatory disorders has been elucidated [33]. Moreover, IL-23R polymorphisms have been related with the progression of various autoimmune diseases [34-37]. The IL-23R signaling pathway is involved in the development of a pathogenic $\mathrm{CD}^{+}$T-cell fate, which is determined by the secretion of TNF- $\alpha$, IL-17, IL-17F and IL-6 [38]. Therefore, considering its important function in the growth and differentiation of lymphocytes, IL-23R might augment the inflammation and production of autoantibodies during the course of a disease [32, 39]. In addition, the possible significance of IL-23 in the inflammatory process was further revealed by a more recent study demonstrating that the Th1-associated transcription factor, T-bet, could enhance the expression of the IL-23 receptor and, finally, the differentiation of Th17 and Th1 cells in autoimmune diseases [40]. In this regard, CK Wong et al. reported that IL-23 promotes the activation of IL-17-producing cells in SLE patients. It is possible that this process is affected by the production of IL-18, which regulates the inflammation of SLE [41]. 


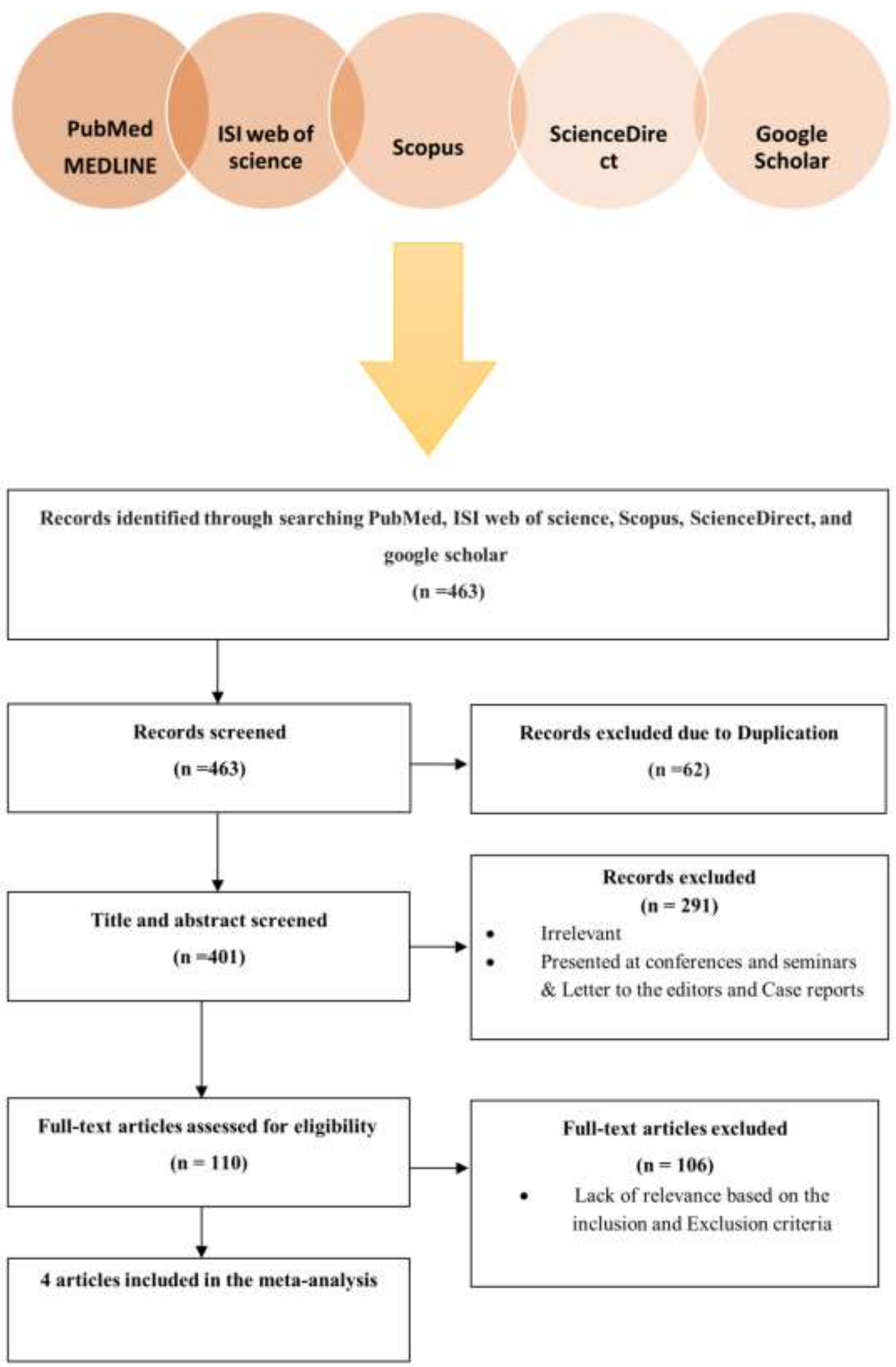

Fig. 1. The procedures for including/ excluding potential studies 
Table 1. Characteristics of studies included in meta-analysis of overall SLE disease

\begin{tabular}{|c|c|c|c|c|c|c|c|c|c|}
\hline $\begin{array}{l}\text { Study } \\
\text { author }\end{array}$ & Year & Country & Ethnicity & Sex & $\begin{array}{c}\text { Total } \\
\text { cases/controls }\end{array}$ & $\begin{array}{c}\text { Case age/ } \\
\text { control age } \\
(\text { Mean } \pm \text { SD) }\end{array}$ & $\begin{array}{l}\text { Genotype } \\
\text { method }\end{array}$ & Outcome & $\begin{array}{l}\text { Quality } \\
\text { score }\end{array}$ \\
\hline $\begin{array}{l}\text { Li et al. } \\
{[26]}\end{array}$ & 2010 & China & Caucasian & $\mathrm{M} / \mathrm{F}$ & $139 / 168$ & $33.5 / 34.5$ & PCR-RFLP & SLE & 7 \\
\hline $\begin{array}{l}\text { Safrany } \\
\text { et al. } \\
{[27]}\end{array}$ & 2010 & Hungarian & Caucasian & $\mathrm{M} / \mathrm{F}$ & $383 / 253$ & NR/NR & PCR-RFLP & SLE & 8 \\
\hline $\begin{array}{l}\text { Sanchez } \\
\text { et al. } \\
{[28]}\end{array}$ & 2007 & Spain & Caucasian & $\mathrm{M} / \mathrm{F}$ & $224 / 342$ & NR/NR & PCR-RFLP & SLE & 8 \\
\hline $\begin{array}{l}\text { Kim et } \\
\text { al. [29] }\end{array}$ & 2009 & S. Korea & Caucasian & $\mathrm{M} / \mathrm{F}$ & $602 / 991$ & $32.4 / 37.4$ & PCR-RFLP & SLE & 7 \\
\hline
\end{tabular}

NR: not reported; M: male; F: female; SLE: systemic lupus erythematosus

Table 2. Distribution of genotype and allele among SLE patients and controls

\begin{tabular}{lcccccccccccc}
\hline \multirow{1}{*}{ Study author } & \multicolumn{9}{c}{ SLE cases } & \multicolumn{7}{c}{ Healthy controls } & P-HWE & MAF \\
& TT & TG & GG & T & G & TT & TG & GG & T & G & & \\
\hline Li et al. [26] & 46 & 59 & 34 & 151 & 127 & 55 & 79 & 34 & 189 & 147 & 0.56 & 0.43 \\
$\begin{array}{l}\text { Safrany et al. } \\
\text { [27] }\end{array}$ & 125 & 176 & 82 & 426 & 340 & 73 & 139 & 41 & 285 & 221 & 0.06 & 0.43 \\
$\begin{array}{l}\text { Sanchez et al. } \\
{[28]}\end{array}$ & 69 & 106 & 49 & 244 & 202 & 121 & 153 & 68 & 395 & 289 & 0.12 & 0.42 \\
Kim et al. [29] & NA & NA & NA & 688 & 516 & NA & NA & NA & 1180 & 802 & NA & 0.40 \\
\hline
\end{tabular}

P-HWE: p-value for Hardy-Weinberg equilibrium; MAF: minor allele frequency of control group; NA: not available. Other abbreviated as Table 1.

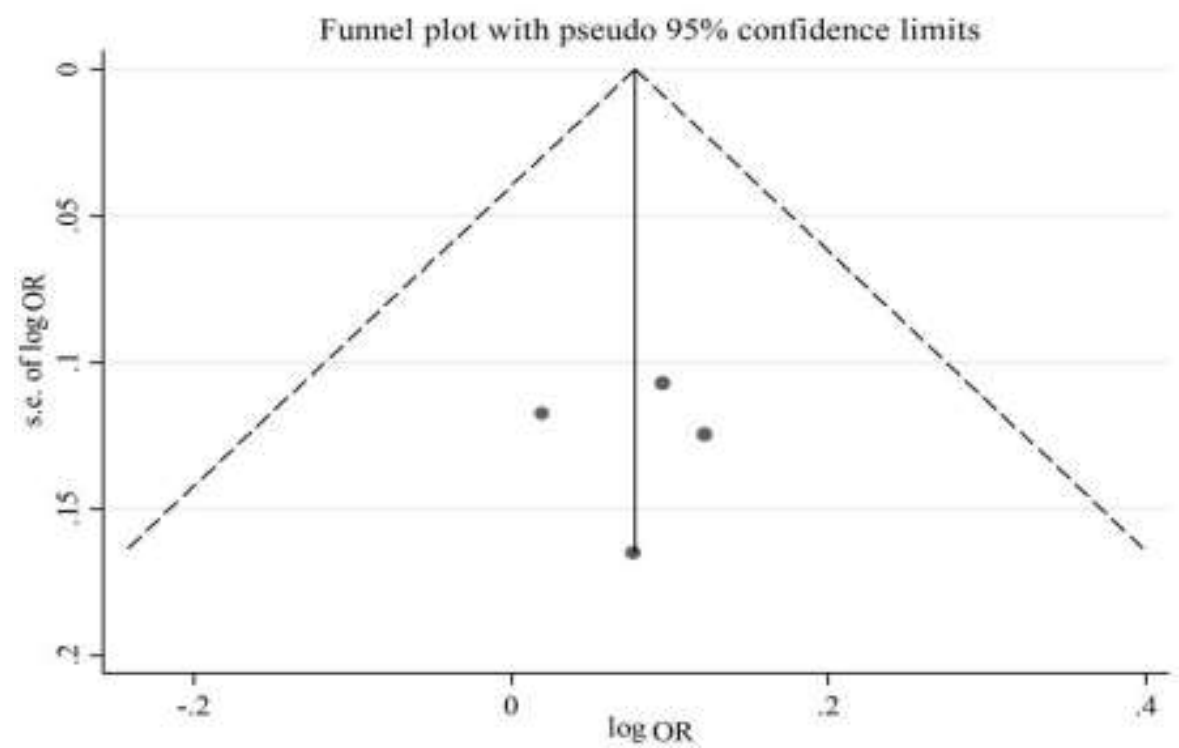

Fig. 2. Funnel plot on IL-23R (rs7517847 T>G) gene SNP to evaluate the publication bias of the literature 


\section{IL-23R gene rs7517847 T>G SNP and SLE}

Table 3. Main results of pooled ORs in meta-analysis of IL-23R (rs7517847) polymorphism

\begin{tabular}{|c|c|c|c|c|c|c|c|c|c|c|}
\hline \multirow[b]{3}{*}{ Disease } & \multirow[b]{3}{*}{ Genetic model } & \multirow{3}{*}{$\begin{array}{l}\text { Sample size } \\
\text { Case/Control }\end{array}$} & \multirow{2}{*}{\multicolumn{2}{|c|}{ Test of association }} & \multirow{2}{*}{\multicolumn{2}{|c|}{$\begin{array}{c}\text { Test of } \\
\text { heterogeneity }\end{array}$}} & \multicolumn{4}{|c|}{ Test of publication bias } \\
\hline & & & & & & & \multicolumn{2}{|c|}{ Begg's } & \multicolumn{2}{|c|}{ Egger's } \\
\hline & & & OR & $95 \% \mathrm{CI}$ & $\mathrm{I}^{2}(\%)$ & $\mathrm{P}$ & Z & $\mathrm{P}$ & $\mathrm{t}$ & $P$ \\
\hline \multirow[t]{5}{*}{ SLE } & Dominant model & $1348 / 1754$ & 0.95 & $0.72-1.18$ & 0.0 & 0.39 & 0.52 & 0.60 & 0.11 & 0.93 \\
\hline & Recessive model & $1348 / 1754$ & 1.13 & $0.80-1.46$ & 0.0 & 0.80 & 0.52 & 0.60 & 0.27 & 0.83 \\
\hline & Allelic model & $1348 / 1754$ & 1.08 & $0.95-1.21$ & 0.0 & 0.94 & 0.0 & 1.0 & 0.01 & 0.99 \\
\hline & GG vs. TT & $1348 / 1754$ & 1.20 & $0.81-1.60$ & 0.0 & 0.97 & 0.52 & 0.60 & 0.23 & 0.85 \\
\hline & TG vs. TT & $1348 / 1754$ & 0.86 & $0.63-1.08$ & 0.0 & 0.50 & 0.52 & 0.60 & 0.06 & 0.96 \\
\hline
\end{tabular}
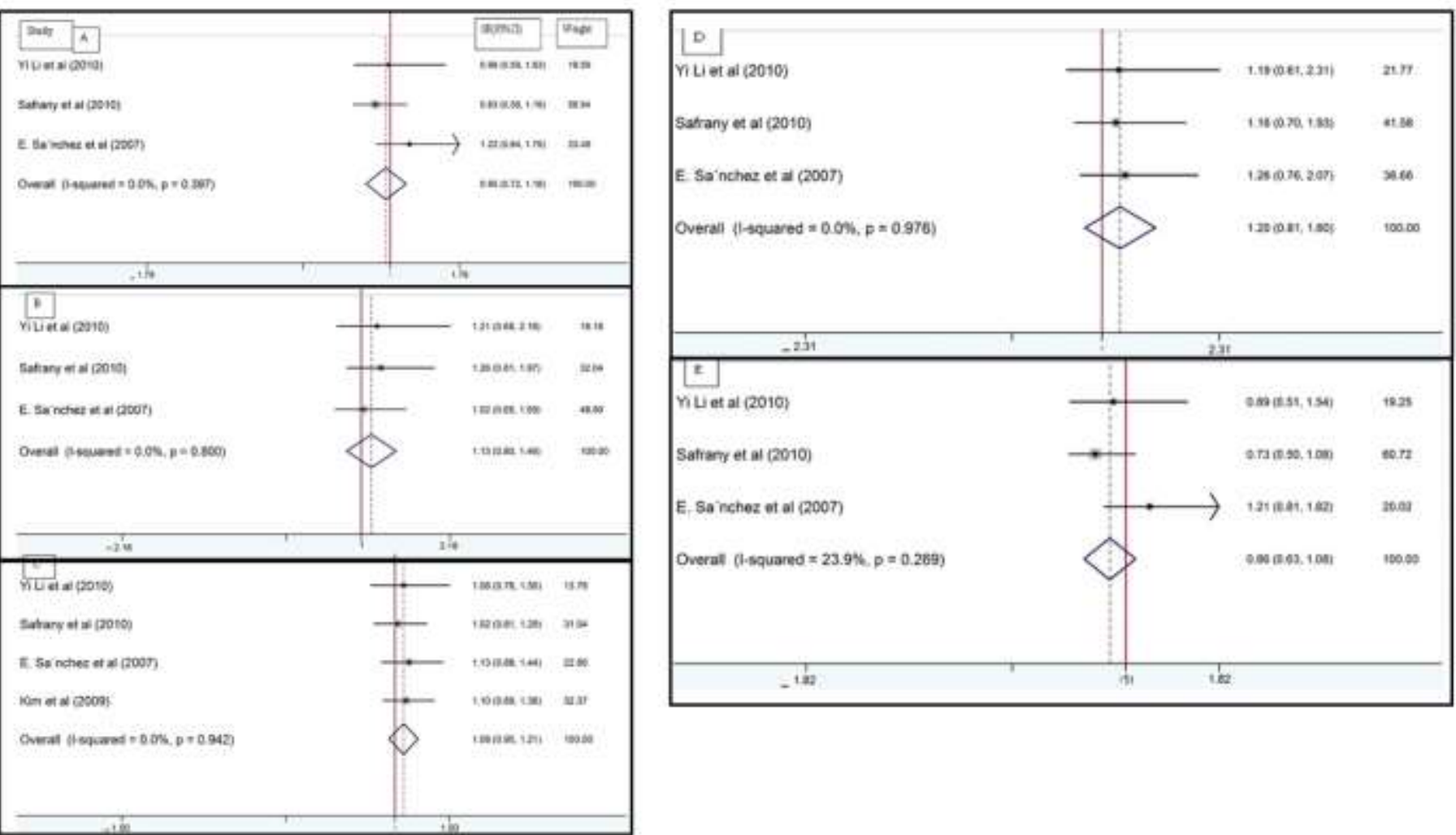

Fig. 3. Forest plot of association between IL-23R (rs7517847 T>G) gene SNP and SLE disease risk. Dominant model (A), Recessive model (B), Allelic model (C), GG vs. TT (D), and TG vs. TT (E)

The present study had some limitations. First, it was based on unadjusted ORs without adjustment for potential confounders; thus, the results should be interpreted with caution. Second, the number of included case-control articles was small. Third, only published English language studies were imported into this meta-analysis, and that probably led to the exclusion of some relevant publications in other languages. Finally, since included studies did not report data regarding the interactions of this polymorphism with other polymorphisms or environmental factors, the potential interactions between gene-gene and gene-environmental factors could not be further evaluated, and this shortage might have affected the results.

Overall, the current study suggests that the IL-23R gene rs7517847 $\mathrm{T}>\mathrm{G}$ SNP is not associated with the risk of SLE. Because of the scarcity of current evidence and to obtain a more conclusive result, additional large-scale and well-designed investigations are necessary to assess the association of the IL-23R gene rs7517847 T>G SNP and SLE risk.

\section{Conclusion}

The current meta-analysis suggests that the IL-23R (rs7517847 T>G) gene SNP might not be related with 
the risk of SLE. More studies are essential to confirm these results.

\section{Conflicts of interest}

The authors declare no conflicts of interest.

\section{Authors' Contributions}

Each author confirms that s/he has participated in the work in a substantive way and is prepared to take full responsibility for the work.

\section{Acknowledgment}

This work was supported by a research grant from the Deputy of Research, Tehran University of Medical Sciences, Tehran, Iran (Grant No. 94-03-41-30267).

\section{References}

1. Love PE, Santoro SA. Antiphospholipid antibodies: anticardiolipin and the lupus anticoagulant in systemic lupus erythematosus (SLE) and in nonSLE disorders: prevalence and clinical significance. Annals of Internal Medicine 1990; 112(9): 682-98. doi: 10.7326/0003-4819112-9-682.

2. Svenungsson E, Jensen-Urstad K, Heimbürger M, Silveira A, Hamsten A, de Faire U. et al. Risk factors for cardiovascular disease in systemic lupus erythematosus. Circulation 2001; 104(16): 1887-93. doi: 10.1161/ hc4101.097518.

3. Danchenko N, Satia J, Anthony M. Epidemiology of systemic lupus erythematosus: a comparison of worldwide disease burden. Lupus 2006; 15(5): 30818. doi: 10.1191/0961203306 $\operatorname{lu} 2305 x x$

4. Agmon-Levin N, Mosca M, Petri M, Shoenfeld Y. Systemic lupus erythematosus one disease or many? Autoimmunity Reviews 2012; 11(8): 593-95. doi: 10.1016/j.autrev.2011.10.020.

5. Deafen D, Escalante A, Weinrib L, Horwitz D, Bachman B, RoyBurman P. et al. A revised estimate of twin concordance in systemic lupus erythematosus. Arthritis \& Rheumatism 1992; 35(3): 311-18. doi: 10.1002/art. 1780350310.

6. Wakeland EK, Liu K, Graham RR, Behrens TW. Delineating the genetic basis of systemic lupus erythematosus. Immunity 2001; 15(3): 397-408. doi: 10.1016/s1074-7613(01)00201-1.

7. De Lema GP, Maier H, Nieto E, Vielhauer V, Luckow B, Mampaso F. et al. Chemokine expression precedes inflammatory cell infiltration and chemokine receptor and cytokine expression during the initiation of murine lupus nephritis. Journal of the American Society of Nephrology 2001; 12(7): 1369-82.

8. Anders HJ, Vielhauer V, Schlöndorff D. Chemokines and chemokine receptors are involved in the resolution or progression of renal disease. Kidney International 2003; 63(2): 40115. doi: 10.1046/j.1523-1755. 2003.00750.x.

9. Tackey E, Lipsky P, Illei G. Rationale for interleukin-6 blockade in systemic lupus erythematosus. Lupus 2004; 13(5): 339-43. doi: 10.1191/ 0961203304lu1023oa.

10. Murphy CA, Langrish CL, Chen $\mathrm{Y}$, Blumenschein $\mathrm{W}, \mathrm{Mc}$ Clanahan T, Kastelein RA. et al. Divergent pro-and antiinflammatory roles for IL-23 and IL-12 in joint autoimmune inflammation. The Journal of Experimental Medicine 2003; 198(12): 1951-57. doi: 10.1084/ jem. 20030896

11. Oppmann B, Lesley R, Blom B, Timans JC, Xu Y, Hunte B. et al. Novel p19 protein engages IL12 p40 to form a cytokine, IL-23, with biological activities similar as well as distinct from IL- 12 . Immunity 2000; 13(5): 715-25. doi: $\quad 10.1016 / \mathrm{s} 1074-7613(00)$ 00070-4.

12. Sutton CE, Lalor SJ, Sweeney $\mathrm{CM}$, Brereton CF, Lavelle EC, Mills KH. Interleukin-1 and IL-23 induce innate IL-17 production from $\gamma \delta \mathrm{T}$ cells, amplifying Th17 responses and autoimmunity. Immunity 2009; 31(2): 331-41. doi: $\quad 10.1016 / j . i m m u n i .2009 .08$. 001.

13. Korn T, Bettelli E, Oukka M, Kuchroo VK. IL-17 and Th17 Cells. Annual Review of
Immunology 2009; 27(1): 485517. doi: 10.1146/annurev. immunol.021908.132710.

14. Lankford CS, Frucht DM. A unique role for IL-23 in promoting cellular immunity. Journal of Leukocyte Biology 2003; 73(1): 49-56. doi: 10.1189/ jlb.0602326.

15. Di Cesare A, Di Meglio P, Nestle FO. The IL-23/Th17 axis in the immunopathogenesis of psoriasis. Journal of Investigative Dermatology 2009; 129(6): 133950. doi: $10.1038 /$ jid.2009.59.

16. Liu Y, Krueger J, Bowcock A. Psoriasis: genetic associations and immune system changes. Genes and Immunity 2007; 8(1): 1-12. doi: 10.1038/sj.gene.6364351.

17. Brown MA. Progress in the genetics of ankylosing spondylitis. Briefings in Functional Genomics 2011; 10(5): 249-57. doi: 10.1093/bfgp/ elr023.

18. Sas TN, Popescu M, Cirla A, Gheonea IA, Popescu AI. THE multidisciplinary approach of graves ophthalmopathy management- a source of competitiveness of the medical tourism in Romania. International Journal for Responsible Tourism 2015; 4(1): 7.

19. Leshinsky-Silver E, Karban A, Dalal I, Eliakim R, Shirin H, Tzofi T. et al. Evaluation of the interleukin-23 receptor gene coding variant $\mathrm{R} 381 \mathrm{Q}$ in pediatric and adult Crohn disease. Journal of Pediatric Gastroenterology and Nutrition 2007; 45(4): 40508. doi: 10.1097/mpg.0b013e 318141a1de.

20. Paradowska-Gorycka A, Grzybowska-Kowalczyk A, Wojtecka-Lukasik E, Maslinski S. IL-23 in the Pathogenesis of 
Rheumatoid Arthritis. Scandinavian Journal of Immunology 2010; 71(3): 13445. doi: 10.1111/j.1365-3083 2009.02361.x.

21. Haase M, Bellomo R, Devarajan P, Schlattmann P, Haase-Fielitz A, Group NM-aI. Accuracy of neutrophil gelatinase-associated lipocalin (NGAL) in diagnosis and prognosis in acute kidney injury: a systematic review and meta-analysis. American Journal of Kidney Diseases 2009; 54(6): 1012-24. doi: 10.1053/j.ajkd. 2009.07.020.

22. Stang A. Critical evaluation of the Newcastle-Ottawa scale for the assessment of the quality of nonrandomized studies in metaanalyses. European Journal of Epidemiology 2010; 25(9): 60305. doi: 10.1007/s10654-0109491-z.

23. Rodriguez S, Gaunt TR, Day IN Hardy-Weinberg equilibrium testing of biological ascertainment for Mendelian randomization studies. American Journal of Epidemiology 2009; 169(4): 505-14. doi: 10.1093/aje/ kwn359.

24. Evangelou E, Ioannidis JP, Patsopoulos NA. Uncertainty in heterogeneity estimates in metaanalyses. BMJ: British Medical Journal 2007; 335(7626): 91416. doi: $10.1136 / \mathrm{bmj} .39343$. 408449.80 .

25. Egger M, Smith GD, Schneider M, Minder C. Bias in metaanalysis detected by a simple, graphical test. $\boldsymbol{B m j ~ 1 9 9 7 ; ~}$ 315(7109): 629-34. doi: 10.1136/ bmj.315.7109.629.

26. Li Y, Liang WB, Li C, Gao LB, Zhou B, Wang YY. et al. The association between interleukin23 receptor gene polymorphisms and systemic lupus erythematosus. DNA and Cell Biology 2010; 29(2): 79-82. doi: 10.1089/dna.2009.0913.

27. Safrany E, Hobor R, Jakab L, Tarr T, Csongei V, Jaromi L. et al. Interleukin-23 receptor gene variants in Hungarian systemic lupus erythematosus patients. Inflammation Research 2010; 59(2): 159-64. doi: 10.1007/ s00011-009-0089-4.

28. Sanchez E, Rueda B, Callejas J, Sabio J, Ortego-Centeno N, Jimenez-Alonso J. et al. Analysis of interleukin-23 receptor (IL23R) gene polymorphisms in systemic lupus erythematosus. Tissue Antigens 2007; 70(3): 233-37. doi: 10.1111/j.13990039.2007.00881.x.

29. Kim HS, Kim I, Kim JO, Bae JS, Shin HD, Bae SC. No association between interleukin 23 receptor gene polymorphisms and systemic lupus erythematosus. Rheumatology International 2009; 30(1): 33-38. doi: 10.1007/s00296-009-0893-8.

30. Gualtierotti R, Biggioggero $\mathrm{M}$, Penatti A, Meroni P. Updating on the pathogenesis of systemic lupus erythematosus. Autoimmunity Reviews 2010; 10(1): 3-7. doi: 10.1016/j.autrev. 2010.09.007

31. Yang J, Chu Y, Yang X, Gao D, Zhu L, Yang X. et al. Th17 and natural Treg cell population dynamics in systemic lupus erythematosus. Arthritis \& Rheumatism 2009; 60(5): 147283. doi: 10.1002/art.24499.

32. Zhang Z, Kyttaris VC, Tsokos GC. The role of IL-23/IL-17 axis in lupus nephritis. The Journal of Immunology 2009; 183(5): 316069. doi: 10.4049/jimmunol. 0900385.

33. Iwakura $\mathrm{Y}$, Ishigame $\mathrm{H}$. The IL23/IL-17 axis in inflammation. The Journal of Clinical Investigation 2006; 116(5): 121822. doi: $10.1172 /$ jci28508.

34. Sáfrány E, Pazar B, Csöngei V, Jaromi L, Polgar N, Sipeky C. et al. Variants of the IL23R gene are associated with ankylosing spondylitis but not with Sjögren syndrome in Hungarian population samples. Scandinavian Journal of Immunology 2009; 70(1): 68-74. doi: $\quad 10.1111 / \mathrm{j} .1365-3083.2009$. 02265.x.

35. Latiano A, Palmieri O, Valvano MR, D'Incà R, Cucchiara $\mathrm{S}$, Riegler G. et al. Replication of interleukin 23 receptor and autophagy-related 16-like 1 association in adult-and pediatriconset. World J Gastroenterol 2008; 14(29): 4643-51. doi 10.3748/wjg.14.4643.

36. Okazaki $\mathrm{T}$, Wang $\mathrm{MH}$, Rawsthorne P, Sargent M, Datta LW, Shugart YY. et al. Contributions of IBD5, IL23R, ATG16L1, and NOD2 to Crohn's disease risk in a population-based case-control study: Evidence of gene-gene interactions. Inflammatory Bowel Diseases 2008; 14(11): 1528-41. doi: 10.1002/ibd.20512.

37. Kim HS, Choi D, Lim LL, Allada G, Smith JR, Austin CR. et al. Association of interleukin 23 receptor gene with sarcoidosis. Disease markers 2011; 31(1): 17 24. doi: 10.1155/2011/185106.

38. McKenzie BS, Kastelein RA, Cua DJ. Understanding the IL-23-IL17 immune pathway. Trends in Immunology 2006; 27(1): 17-23. doi: 10.1016/j.it.2005.10.003.

39. Chen D, Chen Y, Wen M, Hsieh T, Hung W, Lan J. The potential role of Th17 cells and Th17related cytokines in the pathogenesis of lupus nephritis. Lupus 2012; 21(13): 1385-96. doi: 10.1177/0961203312457718.

40. Ivanov II, McKenzie BS, Zhou L, Tadokoro CE, Lepelley A, Lafaille JJ. et al. The orphan nuclear receptor ROR $\gamma \mathrm{t}$ directs the differentiation program of proinflammatory IL-17+ T helper cells. Cell 2006; 126(6): 1121-33. doi: 10.1016/j.cell.2006.07.035.

41. Wong C, Ho CY, Li E, Lam C. Elevation of proinflammatory cytokine (IL-18, IL-17, IL-12) and Th2 cytokine (IL-4) concentrations in patients with systemic lupus erythematosus. Lupus 2000; 9(8): 589-93. doi: 10.1191/096120300678828703. 